\title{
DETERMINAÇÃO DE METAIS EM ÓLEOS LUBRIFICANTES, PROVENIENTES DE MOTORES DE ÔNIBUS URBANO, UTILIZANDO A FAAS
}

\author{
Eva Lúcia Cardoso Silveira, Ronaldo Cunha Coelho, José Machado Moita Neto, Carla Verônica Rodarte de Moura e \\ Edmilson Miranda de Moura* \\ Departamento de Química, Universidade Federal do Piauí, 64049-550 Teresina - PI, Brasil
}

Recebido em 11/12/09; aceito em 12/6/10; publicado na web em 22/9/10

\begin{abstract}
DETERMINATION OF METALS IN LUBRICATING OILS, FROM PUBLIC TRANSPORTATION, USING THE FAAS. This work proposed a procedure to examine ashes produced in burning lubricating oils used in public transportation, in Teresina PI. Sulphanilic acid was added to the oil samples, which were burned at $550{ }^{\circ} \mathrm{C}$ for three hours and $650{ }^{\circ} \mathrm{C}$ for two hours. The ash solutions were analyzed by FAAS and there were significant differences in the metal contents of the waste oil produced from normal car service. The quantification limits in $\mu \mathrm{g} \mathrm{g}{ }^{-1}$ were $5.9(\mathrm{Fe}), 4.4(\mathrm{~Pb}), 1.7(\mathrm{Ni}), 2.1(\mathrm{Cu})$, and 1.2 $(\mathrm{Zn})$. The results showed positive accuracy and precision with recoveries between 88 and 108\%, and RSD lower than $10 \%$.
\end{abstract}

Keywords: used lubricating oil; metals; flame atomic absorption spectrometry.

\section{INTRODUÇÃO}

Os óleos básicos representam o principal componente da grande maioria dos lubrificantes, perfazendo cerca de $80 \%$ da composição. ${ }^{1}$ Os óleos básicos de origem mineral são ainda os mais empregados em lubrificação, sendo obtidos do petróleo, portanto, suas propriedades se relacionam à natureza do óleo cru que lhes deu origem e ao processo de refinação empregado. ${ }^{2,3}$ Geralmente consistem de uma mistura de moléculas contendo de 18 a 40 átomos de carbono classificados em parafínicos, aromáticos e naftênicos (cicloparafínicos). Estes óleos básicos além de carbono e hidrogênio podem conter ainda uma pequena porcentagem de compostos contendo heteroátomos como enxofre, nitrogênio ou oxigênio, substituídos em várias estruturas hidrocarbônicas. ${ }^{4}$ As principais funções dos lubrificantes são: redução do atrito entre superfícies, prevenção de corrosão e ferrugem, resfriamento pela remoção do calor produzido pelo atrito das peças e limpeza do motor, entre outras. ${ }^{5-8}$

O processo de lubrificação hidrodinâmica com óleo consiste em facilitar o movimento relativo entre superfícies sob carga de trabalho usando um filme de óleo lubrificante entre as mesmas. Uma boa lubrificação depende de algumas propriedades, tais como, tolerância ao aquecimento, condutividade térmica, relação entre temperatura, pressão e viscosidade, solvência, dispersância, detergência, antidesgaste, anticorrosão, propriedades de fricção e capacidade antioxidante, que são importantes para o sucesso da lubrificação. Muitas dessas propriedades são controladas pelos aditivos químicos designados para tais finalidades. ${ }^{4}$

$\mathrm{O}$ aperfeiçoamento das máquinas que operam sob condições severas teve como consequência a necessidade da melhoria das qualidades naturais dos lubrificantes denominados óleos minerais puros. ${ }^{8}$ Assim, aditivos são incorporados aos óleos lubrificantes para melhorar sua cor, viscosidade, ponto de fluidez, capacidade antidesgaste, propriedades anticorrosivas e antioxidativas. ${ }^{9} \mathrm{Um}$ típico óleo de motor novo é constituído de poliol ésteres (94-97\%), antioxidantes (2-4\%), antidesgaste/agentes de extrema pressão $(1-3 \%)$, inibidores de corrosão $(<0,5 \%)$, inibidores de ferrugem $(<0,5 \%)$ e agentes antiespumantes (na ordem de $\left.\mathrm{mg} \mathrm{L}^{-1}\right) .{ }^{10}$ Tais aditivos são adicionados aos óleos básicos afim de produzir carac-

*e-mail: mmoura@ufpi.edu.br terísticas específicas de desempenho para operação em condições severas. Dessa forma, o óleo básico funciona como um solvente para os aditivos, controlando o volume e propriedades da superfície. ${ }^{4}$ Esses aditivos contêm metais, tais como, bário, cálcio, zinco, chumbo, cromo, magnésio, antimônio, níquel, cádmio, mercúrio e molibdênio, que são adicionados ao óleo novo como composto organometálico, para melhorar o desempenho do óleo sob condições severas. ${ }^{7,9-12}$ Durante o trabalho do motor, os aditivos perdem suas características iniciais e metais como ferro, cobre, cádmio, zinco, níquel e chumbo aparecem no óleo, originados do desgaste das ligas metálicas que compõem as peças do motor. Dessa forma, as concentrações desses metais tendem a aumentar com o uso do óleo. ${ }^{12-15}$

A determinação de certos metais em óleos lubrificantes usados é uma prática usual na manutenção das máquinas ${ }^{16}$ e vem sendo implementada como uma parte do programa de manutenção preditiva ou proativa. $\mathrm{Na}$ manutenção preditiva, as propriedades físicoquímicas do óleo são estudadas para determinar o tempo apropriado para substituí-lo ${ }^{17,18}$ e o desgaste do motor é monitorado através dos teores de metais no óleo. Dessa forma, a determinação de metais de desgaste em óleos lubrificantes usados é muito útil para prevenir componentes de falhas do motor, controlar a qualidade do motor e identificar algumas adulterações específicas. ${ }^{19-21}$

Este trabalho teve como objetivo determinar os teores dos metais $\mathrm{Fe}, \mathrm{Pb}, \mathrm{Ni}, \mathrm{Cu}$ e $\mathrm{Zn}$ em óleos lubrificantes usados, provenientes de carros com diferentes motores e diferentes quilometragens por espectrometria de absorção atômica com atomização em chama.

\section{PARTE EXPERIMENTAL}

\section{Seleção e coleta das amostras de óleos lubrificantes}

As amostras de óleo lubrificante novo e usado, grau de viscosidade SAE 15W40, foram obtidas em uma empresa de ônibus de transporte urbano de Teresina - PI. Os óleos lubrificantes usados foram coletados durante a operação de troca do óleo dos veículos automotivos após percorrerem 15000, 20000, 25000 e $30000 \mathrm{~km}$ com o lubrificante. As amostras foram estocadas em frascos de polietileno em temperatura ambiente. Os veículos foram selecionados de acordo com o tipo de motor e ano de fabricação, conforme Tabela 1. 
Tabela 1. Descrição dos veículos selecionados para análise

\begin{tabular}{cccc}
\hline Amostra & Ano do carro & Marca do carro* & Tipo do motor \\
\hline A & 1997 & BM & OM 366 LA \\
B & 1998 & BM & OM 366 LA \\
C & 1999 & BM & OM 366 LA \\
D & 2000 & WA & 610 TCA MWM \\
\hline
\end{tabular}

*Símbolos criados pelos autores

\section{Soluções e reagentes}

A limpeza de todos os materiais utilizados foi efetuada com solução de detergente, posteriormente lavados com água deionizada e, em seguida, imersos, no mínimo por $24 \mathrm{~h}$ em solução $10 \%$ v/v de $\mathrm{HNO}_{3}$ P.A. Finalmente, foram enxaguados com água deionizada e colocados em um ambiente isento de poeira para secagem.

Todas as soluções foram preparadas com reagentes de grau de pureza analítica (Merck, Aldrich, Fluka) e água deionizada de alta pureza (resistividade $18 \mathrm{M} \Omega \mathrm{cm}^{-1}$ ) purificada através do sistema MilliQ (Millipore, Bedford, MA, USA). As soluções de referência, para obtenção da curva analítica dos metais, foram preparadas através de diluição serial das soluções estoque em $\mathrm{HNO}_{3}$, ajustando-se o $\mathrm{pH}$ ao da solução da amostra. A curva de calibração foi construída utilizando sempre seis concentrações diferentes dos padrões metálicos.

\section{Procedimento analítico}

Uma mistura de 10,0 g (obtida após uma vigorosa agitação mecânica para homogeneizar o material particulado) de óleo lubrificante e $1,0 \mathrm{~g}$ de ácido sulfanílico foi colocada em um copo Béquer de $100 \mathrm{~mL}$ e aquecida até evaporar toda a parte líquida. $\mathrm{O}$ resíduo formado foi posteriormente conduzido para mufla com temperatura inicial de $25{ }^{\circ} \mathrm{C}$ e a temperatura foi aumentada até atingir $550{ }^{\circ} \mathrm{C}$, permanecendo nessa temperatura por $3 \mathrm{~h} \mathrm{e}$, em seguida, aumentou-se a temperatura da mufla para $650{ }^{\circ} \mathrm{C}$ por mais $2 \mathrm{~h}$. A cinza obtida foi dissolvida em $3 \mathrm{~mL}$ de $\mathrm{HCl}$ concentrado e transferida para um balão de $100 \mathrm{~mL}$. Adicionaram-se $30 \mathrm{~mL}$ de solução de lantânio $10000 \mathrm{mg} \mathrm{L}^{-1}$, preparada a partir de nitrato de lantânio e completou-se o volume com água deionizada. As análises foram realizadas em triplicata. ${ }^{22}$

\section{Análise instrumental por espectrometria de absorção atômica}

As concentrações dos metais em todas as soluções foram determinadas através de análise por espectrômetria de absorção atômica, modelo SpectraAA 220FS Varian, GTA 100, equipado com correção de fundo com lâmpada de deutério e operando com corrente da lâmpada de cátodo oco, banda espectral de passagem e os seguintes comprimentos de onda respectivamente $10,0 \mathrm{~mA} ; 0,2$ e $248,3 \mathrm{~nm}$ (Fe); 5,0 mA; 1,0 e 217,0 nm (Pb); 4,0 mA; 0,2 e 232,0 nm (Ni); 5,0 $\mathrm{mA} ; 1,0$ e 213,9 nm (Zn) e 10,0 mA; 1,0 e 324,7 nm (Cu).

\section{Procedimento para teste de recuperação}

A recuperação (ou fator de recuperação) $\mathrm{R}$ é definida como a proporção da quantidade da substância de interesse, presente ou adicionada na porção analítica do material teste, que é extraída e passível de ser quantificada. ${ }^{23}$ Foram feitos estudos de recuperação para avaliar a exatidão do método. Tais estudos consistiram na fortificação das amostras, com concentrações conhecidas do analito, em diferentes níveis, seguida da determinação da concentração da amostra adicionada.

\section{RESULTADOS E DISCUSSÃO}

\section{Avaliação do método}

Os testes de recuperação propiciaram valores para $\mathrm{Fe}, \mathrm{Pb}, \mathrm{Ni}, \mathrm{Zn}$ e $\mathrm{Cu}$ iguais a 101,$0 ; 88,0 ; 103,0,108$ e 92,0\%, respectivamente. O método apresentou precisão satisfatória; analisaram-se as amostras fortificadas em triplicata e os resultados obtidos foram bem próximos entre si, os desvios padrão relativos foram inferiores a $10 \%$. Os intervalos aceitáveis de recuperação para análise de resíduos geralmente estão entre 70 e $120 \%$, com precisão de até $\pm 20 \%$. Porém, dependendo da complexidade analítica e da amostra, este valor pode ser de 50 a $120 \%$, com precisão de até $\pm 15 \% .{ }^{23}$ Os limites de quantificação obtidos para este método foram $5,9 \mu \mathrm{g} \mathrm{g}^{-1}$ para $\mathrm{Fe} ; 4,4 \mu \mathrm{g} \mathrm{g}^{-1}$ para $\mathrm{Pb}$; $1,7 \mu \mathrm{g} \mathrm{g}^{-1}$ para Ni; $2,1 \mu \mathrm{g} \mathrm{g}^{-1}$ para Cu e $1,2 \mu \mathrm{g} \mathrm{g}^{-1}$ para $\mathrm{Zn}$.

\section{Análise de metais em óleos lubrificantes}

Óleo lubrificante é uma matriz complexa, e um procedimento analítico para determinação de metais sem um tratamento prévio é dificultado devido à alta viscosidade da amostra. Uma opção seria uma diluição prévia em solvente orgânico para posterior análise, , $^{15,17,19,24}$ porém como o óleo analisado contém metais provenientes do desgaste físico das peças automotivas e esses não dissolvem em solventes orgânicos, fez-se necessária uma etapa de mineralização das amostras.

O ácido sulfanílico (P. A.) foi usado como agente de liberação das cinzas, conforme descrito por Ekanem. ${ }^{9}$ Para evitar interferências causadas pela matriz da amostra, uma solução de nitrato de lantânio foi adicionada durante o preparo das amostras. A solução de nitrato de lantânio permite evitar interferências de fosfato devido à baixa solubilidade do fosfato de lantânio (produto de solubilidade do $\mathrm{LaPO}_{4}=3,7 \times 10^{-23}$ ), obtendo-se assim, resultados mais exatos na determinação dos metais. ${ }^{11}$ A temperatura ótima de calcinação de amostras de óleos lubrificantes é um parâmetro que apresenta muitas controvérsias. ${ }^{9,11,14,15,22}$ Neste trabalho, calcinou-se a amostra por $3 \mathrm{~h}$ a $550{ }^{\circ} \mathrm{C}$ e, a seguir, $2 \mathrm{~h}$ a $650{ }^{\circ} \mathrm{C}$; sendo a menor temperatura e o menor tempo encontrados para obtenção de uma cinza solúvel em $\mathrm{HCl}$ concentrado. $\mathrm{O}$ presente procedimento elimina a necessidade de filtração da solução da cinza, evitando contaminação da amostra ou perda do analito durante a filtração.

Os métodos usados para múltiplas comparações estão contidos na categoria geral da análise de variância, muitas vezes conhecido pelo acrônimo ANOVA (analysis of variance). ${ }^{25}$ Esses métodos usam um teste único para determinar diferenças entre as médias de populações em vez de comparações pareadas, como são feitas com o teste-t. Após a ANOVA indicar uma diferença potencial, procedimentos de comparação múltipla podem ser empregados para identificar quais médias específicas de populações diferem das outras.

Neste trabalho, avaliou-se a influência de três fatores que poderiam influenciar no teor de metais presentes no óleo lubrificante usado: quilometragem percorrida pelo veículo, ano de fabricação e marca do veículo no teor de metais presentes no óleo lubrificante usado. Foram considerados estatisticamente diferentes os resultados que apresentaram probabilidade de ocorrência da hipótese de nulidade menor que 5\% (P<0,05) aplicando-se ANOVA, seguindo de comparações múltiplas pelo teste de Tukey. Aplicou-se teste-t para verificar a influência da marca do motor do veículo. Todas as análises foram realizadas usando o programa SPSS 13.0 for Windows. Os resultados do tratamento estatístico, mostrados nas Figuras 1 a 5 , evidenciam um aumento na concentração de todos os metais encontrados nos óleos lubrificantes usados quando comparados com aqueles encontrados nos óleos lubrificantes novos. Vale ressaltar que o número de amostras analisadas foi relativamente pequeno, 
ou seja, ainda não é possível fazer generalizações, mas sim mostrar tendências neste sentido.

\section{O teor de ferro}

O elemento ferro não é adicionado aos lubrificantes como aditivo, portanto, sua origem na amostra de óleo lubrificante novo $(3,15 \pm 0,03$ $\mu \mathrm{g}^{-1}$ ) pode ser proveniente do próprio óleo utilizado ou de algum tipo de contaminação, possivelmente, adquirida durante o transporte e/ou armazenamento do lubrificante ${ }^{13}$ Como pode ser visto na Figura 1 , todas as amostras de óleo usado apresentaram um aumento na concentração de ferro, com exceção da amostra A para $30000 \mathrm{~km}$. Entretanto, o teste Tukey permite afirmar que tal aumento só é significativo $(\mathrm{p}<0,05)$ em relação às amostras de $25000 \mathrm{~km}$, isto ocorre devido ao desgaste das peças que constituem os motores desses automóveis, tais como, cilindros, pistões, engrenagens, anéis, eixos, bomba de óleo, virabrequim, pontos de apoio, etc. ${ }^{9,22}$ Alguns fatores contribuem para o aumento desse desgaste como, por exemplo, a qualidade do percurso realizado pelo veículo, o modo como o motorista conduz o veículo, a presença de contaminantes (fuligem, poeira, água, ácidos, etc) presentes no lubrificante. Normalmente as empresas colocam os carros mais velhos para realizarem percursos mais longos e de piores qualidades (sem pavimentação e/ou com esta em situação muito precária), isto faz com que os motores sejam forçados, gastando mais combustível e produzindo mais desgaste, o que transfere uma maior quantidade de resíduos para o lubrificante. Estes resíduos provocam uma redução na eficiência da lubrificação, devido à oxidação de alguns de seus componentes e, como consequência, as superfícies das peças metálicas que constituem o motor sofrem um maior desgaste. ${ }^{13}$

Observa-se ainda que o teor de ferro é muito maior na amostra A (1997) e é significativamente diferente quando comparado ao óleo novo e também ao óleo usado da amostra D (WA), pois esta amostra é proveniente do carro mais velho, que geralmente é colocado para circular em percurso de pavimentação ruim. Segundo informações do pessoal da empresa fornecedora do óleo usado, o carro A (1997) foi colocado para circular em percurso de pavimentação ruim, na quilometragem de $15000 \mathrm{~km}$, quando houve a troca do óleo, entretanto, o mesmo procedimento não ocorreu nas demais quilometragens (20000, 25000 e $30000 \mathrm{~km})$ para evitar maiores problemas com a mecânica desse automóvel. Sendo assim, analisando os resultados mostrados na Figura 1, pode-se sugerir que o aumento no teor de $\mathrm{Fe}$ nas amostras de óleos usados está diretamente relacionado com a qualidade do percurso percorrido pelo automóvel.

Aplicou-se teste-t para amostras independentes e observou-se que os teores de ferro presentes nas amostras analisadas sofrem também influência da marca do motor, ou seja, pode-se observar que o automóvel da marca BM (Tabela 1) sofre um maior desgaste na sua mecânica do que o veículo da marca WA (Tabela 1), pois o teor de ferro encontrado nos óleos lubrificantes do veículo D foi estatisticamente inferior àqueles encontrados para os veículos $\mathrm{A}, \mathrm{B}, \mathrm{e} \mathrm{C}$.

\section{O teor de cobre}

O metal cobre não é adicionado ao óleo lubrificante como aditivo, e a presença deste metal em amostras de óleos lubrificantes usados geralmente ocorre devido ao desgaste de guias de válvula, anéis de pistão, pontos de apoio, etc. ${ }^{22}$ Observa-se na Figura 2 que todas as amostras de óleo lubrificante usado apresentaram um aumento na concentração deste metal, em relação à quilometragem, no entanto, somente para $15000 \mathrm{~km}$ este aumento é estatisticamente significativo. Em relação à variável ano de fabricação do veículo verificou-se uma diferença significativa entre os teores de $\mathrm{Cu}$ do óleo novo e das amostras A (1997) e B (1998), assim como também entre a amostra A (1997) e as amostras C (1999) e D (2000). Quanto à marca do carro, também há uma diferença significativa, pois a amostra $\mathrm{D}$ apresenta os menores teores de $\mathrm{Cu}$.

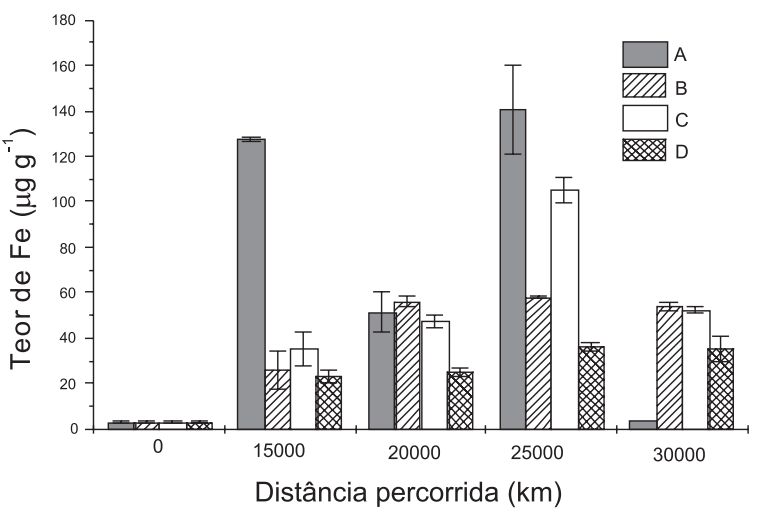

Figura 1. Teores de Fe nas amostras A (1997), B (1998), C (1999) e D (2000) em função da distância percorrida

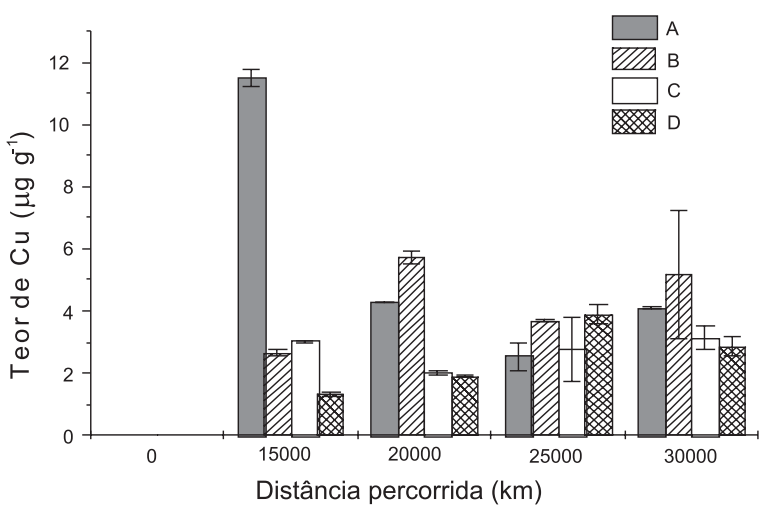

Figura 2. Teores de Cu nas amostras A (1997), B (1998), C (1999) e D (2000) em função da distância percorrida

\section{O teor de níquel}

Os aditivos organometálicos contendo níquel são adicionados em pequenas quantidades ao óleo lubrificante como aditivo antidesgaste, 22 mas nas amostras de óleo novo analisadas, os teores de níquel apresentaramse abaixo do limite de detecção do método. Entretanto, observa-se na Figura 3 que as amostras A, B e C apresentaram presença de níquel em pequenas quantidades, pois o mesmo pode ser originado do desgaste de pontos de apoio, válvulas, engrenagens (revestida com esse metal), etc. No veículo da marca WA (amostra D e motor 610 TCA MWM) somente em uma amostra, $25000 \mathrm{~km}$, foi detectado Ni e em quantidade menor do que aquelas encontradas nas outras amostras analisadas. Estes resultados sugerem que as peças metálicas desse veículo, que contêm níquel, não sofreram desgastes significativos.

Em relação ao fator quilometragem há uma diferença significativa entre os teores de níquel no óleo novo e amostras de óleos usados recolhidos quando o veículo tinha percorrido $25000 \mathrm{~km}$, distância em que há um aumento no teor deste metal para todas as amostras A, B, C e D. Quanto ao ano do carro, verificou-se diferença significativa entre os teores de níquel no óleo novo e na amostra A (1997), entre amostra D (20000) e amostras A, B e C, pois a amostra D apresentou teores de níquel abaixo do limite de quantificação do método em todas as quilometragens. Quanto à marca do carro, também se verificou através do teste-t uma diferença significativa, pois a amostra D destaca-se das demais amostras A, B e C, podendo-se inferir que o veículo D sofre um menor desgaste nas peças metálicas contendo níquel.

\section{O teor de chumbo}

Complexos orgânicos de chumbo geralmente são adicionados ao óleo lubrificante como aditivo de extrema pressão, ${ }^{22}$ porém, a 


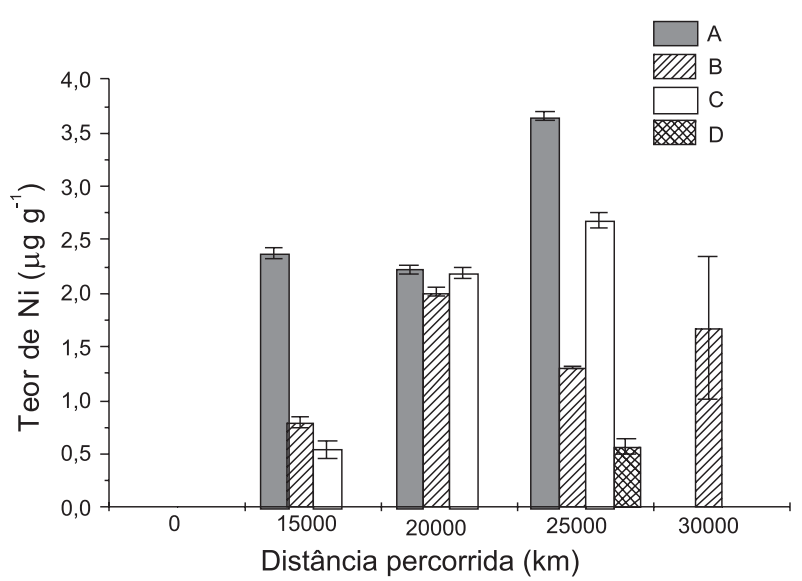

Figura 3. Teores de Ni nas amostras A (1997), B (1998), C(1999) e D (2000) em função da distância percorrida

amostra de óleo novo apresentou teores de chumbo abaixo do limite de detecção do método. Os teores de chumbo em função da distância percorrida com o óleo lubrificante são mostrados na Figura 4. Foi possível detectar e quantificar a presença de chumbo em todas as amostras de óleo usado devido a um possível desgaste dos pontos de apoio e mancais. O elemento chumbo faz parte de uma liga metálica chamada Gun Metal, utilizada na fabricação de mancais para veículos automotivos, cuja concentração varia de 1 a $6 \%$ em massa. ${ }^{13}$ Para o fator quilometragem, observou-se que os teores de chumbo na amostra de óleo novo só apresentam diferença significativa em relação às amostras recolhidas a $30000 \mathrm{~km}$. As amostras de óleos usados recolhidos quando o veículo tinha percorrido $30000 \mathrm{~km}$ apresentaram teores significativamente diferentes quando comparados a todas as outras quilometragens, pois nesta quilometragem há um aumento significativo nos teores de chumbo para todas as amostras.

Os teores de chumbo não apresentaram diferença significativa em relação ao ano de fabricação e marca do motor do veículo.

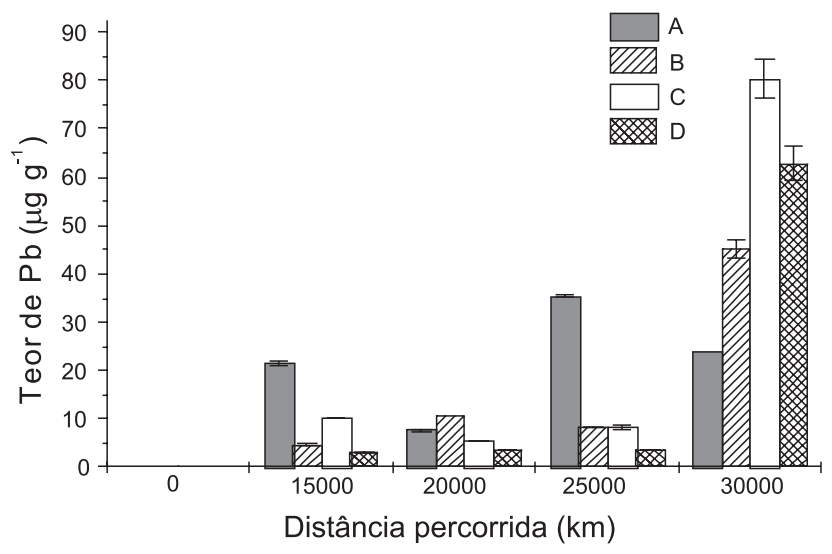

Figura 4. Teores de Pb nas amostras A (1997), B (1998), C (1999) e D (2000) em função da distância percorrida

\section{Teor de zinco}

O metal zinco é adicionado ao óleo lubrificante na forma de dialquilditiofosfato de zinco (ZnDDP) como aditivo multifuncional, desempenhando as funções antioxidante, inibidor de corrosão, antidesgaste, detergente e extrema-pressão. Portanto, o óleo lubrificante contém uma quantidade razoável de zinco como um complexo organometálico. A quantidade inicial de zinco no óleo lubrificante novo foi $1231 \pm 30 \mu \mathrm{g} \mathrm{g}^{-1}$. O desgaste de sistemas galvanizados é a principal fonte de aumento na concentração de zinco em óleos lubrificantes usados. ${ }^{22}$

Os teores de zinco em função da distância percorrida são mostrados na Figura 5. Para a variável quilometragem, quando se compara o teor de zinco encontrado no óleo novo com aqueles encontrados nos óleos usados, verifica-se que houve uma diferença significativa somente para as amostras recolhidas quando os veículos tinham percorrido $30.000 \mathrm{~km}$. Comparando os resultados encontrados (entre os óleos usados) nas amostras recolhidas após os veículos percorrem $30000 \mathrm{~km}$, verifica-se que os teores de $\mathrm{Zn}$ encontrados nessas amostras são inferiores a aqueles encontrados nas outras quilometragens (15000, 20000 e $25000 \mathrm{~km})$ investigadas.

Assim como para o chumbo, os teores de zinco não apresentam diferenças significativas em relação aos fatores ano de fabricação e marca do veículo.

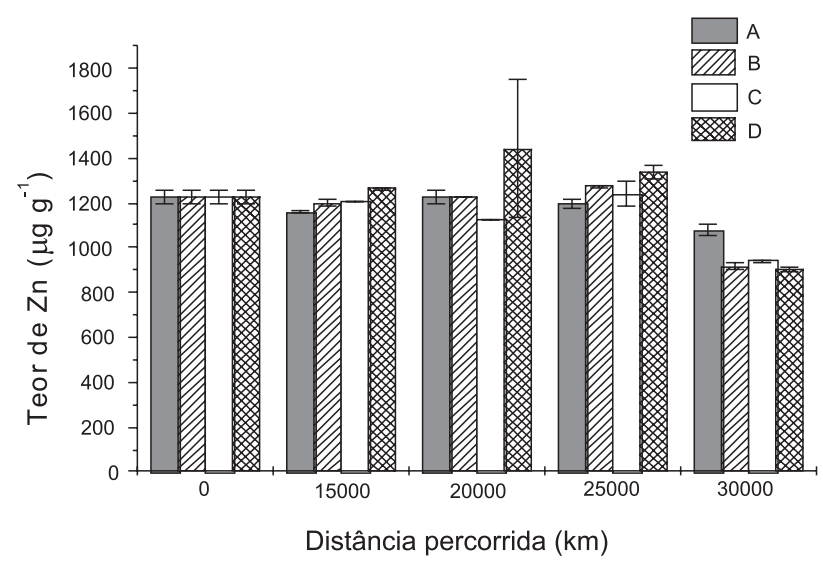

Figura 5. Teores de Zn nas amostras A (1997), B (1998), C (1999) e D (2000) em função da distância percorrida

\section{CONCLUSÃO}

As amostras de óleo usado apresentaram uma tendência de aumento na concentração de todos os metais analisados em relação ao óleo novo, sugerindo ainda que o aumento na concentração, desses metais, está relacionado com a qualidade das peças que constituem os motores e o tipo de percurso realizado pelo veículo. Os resultados aqui expostos permitem sugerir que a presença de $\mathrm{Fe}, \mathrm{Cu}$ e Ni em óleos lubrificantes usados é influenciada pelos fatores: ano de fabricação, distância percorrida e tipo do motor do veículo, enquanto os teores de $\mathrm{Pb}$ e $\mathrm{Zn}$ nas amostras analisadas não sofreram influência do ano de fabricação e nem do tipo do motor.

\section{AGRADECIMENTOS}

À FINEP/FAPEPI pelo apoio financeiro, CAPES pela bolsa concedida e ao Laboratório de Análise de Petróleo (LAPETRO) da UFPI pela permissão para utilização dos equipamentos.

\section{REFERÊNCIAS}

1. Gamlin, C. D.; Dutta, N. K.; Choudhury, N. R.; Kehoe, D.; Matisons, J.; Termochim. Acta 2002, 392, 357.

2. Borin, A.; Poppi, R. J.; J. Braz. Chem. Soc. 2004, 15, 570.

3. Carreteiro, R. P.; Moura, C. R. S.; Lubrificantes e lubrificação, $2^{\mathrm{a}}$ ed., Técnica: Rio de Janeiro, 1988.

4. Hsu, S. M.; Tribol. Int. 2004, 37, 553.

5. Rakic, R.; Tribol. Int. 2004, 37, 365.

6. Borin, A.; Poppi, R. J.; Vib. Spectrosc. 2005, 37, 27. 
7. Aucélio, R. Q.; Souza, R. M.; Campos, R. C.; Miekeley, N.; Silveira, C. L. P.; Spectrochim. Acta, Part B 2007, 62, 952.

8. Sychra, V.; Lang, I.; Sebor, G.; Prog. Anal. At. Spectrosc. 1981, 4, 341.

9. Ekanem, E. J.; Lori, J. A.; Thomas, S. A.; Talanta 1997, 44, 2103.

10. Allahar, K. N.; Butt, D. P.; Orazem, M. E.; Chin, H. A.; Danko, G.; Ogden, W.; Yungk, R. E.; Electrochim. Acta 2006, 51, 1497.

11. Udoh, A. P.; Talanta 1995, 42, 1827.

12. Gonçalves, I. M.; Murillo, M.; González, A. M.; Talanta 1998, 46, 1033

13. Silveira, E. L. C.; Caland, L. B.; Moura, C. V. R.; Moura, E. M.; Quim. Nova 2006, 29, 1193.

14. Zieba-Palus, J.; Koscielniak, P.; Forensic Science International 2000, $112,81$.

15. Zieba-Palus, J.; Forensic Science International 1998, 91, 171.

16. Knochen, M.; Sixto, A.; Pignalosa, G.; Domenech, S.; Garrigues, S.; Guardia, M.; Talanta 2004, 64, 1359.

17. Reis, B. F.; Knochen, M.; Pignalosa, G.; Cabrera, N.; Giglio, A.; Talanta 2004, 64, 1220.
18. Burguera, J. L.; Burguera, M.; Antón, R. E.; Salager, J.; Arandia, M. A.; Rondon, C.; Carrero, P.; Pena, Y. P.; Brunetto, R.; Gallignani, M.; Talanta 2005, 68, 179.

19. Munoz, R. A. A.; Oliveira, P. V.; Angnes, L.; Talanta 2006, 68, 850.

20. Pouzar, M.; Cernohorský, T.; Krejcová, A.; Talanta 2001, 54, 829.

21. Caneca, A. R.; Pimentel, M. F.; Galvão, R. K. H. G.; Matta, C. E.; Carvalho, F. R.; Raimundo Jr.; I. M.; Pasquini, C. P.; Rohwedder, J. J. R.; Talanta 2006, 70, 344.

22. Singh, S. K.; Agarwal, A. K.; Sharma, M.; Appl. Therm. Eng. 2006, 26, 259.

23. Ribani, M.; Bottoli, C. B. G.; Collins, C. H.; Jardim, I. C. S. F.; Melo, L. F. C.; Quim. Nova 2004, 27, 771.

24. Amorim, F. A. C.; Lima, D. C.; Amaro, J. A. A.; Vale, G. R.; Ferreira, S. L. C.; J. Braz. Chem. Soc. 2007, 18, 1566.

25. Skoog, D. A.; West, D. M.; Holler, F. J.; Crouch, S. R.; Fundamentos de Química Analítica, $8^{\mathrm{a}}$ ed., Pioneira Thomson Learning: São Paulo, 200, 2006. 